bảo mép vết thương liền chắc không bi toác vết mổ khi va chạm. Các tác giả khác như Aboulwafa Ahmed and Emara Sherif (2013)[2]: trung bình sau 2 tuần bệnh nhân được cắt chỉ, còn theo nghiên cứu của Haluk Özcanli và cs (2014) [7]: BN được cắt chỉ sau 10 -14 ngày.

\section{KẾT LUÂNN}

Qua quá trình nghiên cứu chúng tôi nhận thây: Mỗi loại vạt đều có ưu và nhược điểm riêng: Vạt ngẫu nhiên có ưu điểm kỹ thuật đơn giản, khả năng sống của vạt tốt, nhưng có nhược điểm là vạt có kích thước nhỏ khả năng di chuyển của vạt kém. Vạt trục mạch đặc biệt là vạt trục mạch cuống nuôi ngược dòng có ưu điểm là vạt có kích thước lớn khả năng di chuyển của vạt linh hoạt nhưng có nhược điểm là vạt thường xuyên bị ứ máu tĩnh mạch và mức độ sống không cao. Do đó không có vạt nào là ưu tiên tuyệt đối trong tạo hình KHPM NT, việc lựa chọn vạt áp dụng phải đảm bảo cân bằng giữa mục tiểu tạo hình nơi nhận vạt và ảnh hưởng của nơi cho.

\section{TÀI LIÊU THAM KHẢO}

1. Beasley, R.W. (1983). Principles of soft tissue replacement for the hand. The Journal of Hand Surgery 8(5):781-784.

2. Aboulwafa, A. and S. Emara (2013). Versatility of Homodigital Islandized Lateral $V-Y$ Flap for Reconstruction of Fingertips and Amputation Stumps. Egypt, J. Plast. Reconstr. Surg., Vol. 37, No. 1, January: 89-96, 2013.

3. Jung Soo Lee, M., PhD, Yeo Hyun (2019) Factors associated with limited hand motion after hand trauma. Wolters Kluwer Health, Inc, 98(3):e14183.

4. B, G. and M. G. (1995). An extended frst dorsal metacarpal artery neurovascular island flap. J Hand Surg, 20:529-531.

5. Özcanli, H., et al. (2015). Reconstruction of fngertip defects with digital artery perforator flap. Acta Orthop Traumatol Turc, 49(1):18-22.

6. Michel Saint-Cyr, et al. (2009). The Perforasome Theory: Vascular Anatomy and Clinical Implications. Plast Reconstr Surg, 2009 Nov; 124(5):1529-1544.

7. Özcanli, H., et al. (2015). Reconstruction of fingertip defects with digital artery perforator flap. Acta Orthop Traumatol Turc 49(1):18-22.

\title{
ĐẶC ĐIỂM LÂM SÀNG VÀ X-QUANG RĂNG HÀM SỮA CÓ CHỈ ĐỊNH ĐIỀU TRI TUỶ BUỒNG
}

Trần Thị Mỹ Hạnh ${ }^{1}$, Nguyễn Hà Thu ${ }^{1}$, Đào Thị Hằng Nga ${ }^{1}$, Nguyễn Vũ Thái Liên ${ }^{2}$

\section{TÓM TẮT}

Mục tiêu: Mô tả đặc điểm lâm sàng và $X$-quang của các răng hàm sũa ở trẻ 3-8 tuổi có chỉ định điều trị tuỷ buồng. Đối tượng và phương pháp nghiên cứu: Nghiên cứu mô tả cắt ngang được thực hiện trên 136 răng hàm sữa có chỉ đinh điều tri tuỷ buồng ở 50 bệnh nhân trẻ em từ 3 đến 8 tuổi, đến khám và điều trị tại Viện Đào tạo Răng Hàm Mặt, Trường Đại học Y Hà Nội năm 2018-2021. Các răng hàm sữa đạt tiêu chuẩn lựa chọn được mô tả các triêu chứng lâm sàng (gồm có: loại răng; vị trí, kích thước lố sâu; tính chất đáy lố sâu), X-quang (giai đoạn tiêu chân răng sữa) và các đặc điểm chung của bệnh nhân (tuổi, giới). Kết quả: Trong 50 bệnh nhân trẻ em được khám và điều trị tuỷ buồng, số trẻ nam ( 28 trẻ, chiếm $56,00 \%$ ) cao gấp 1,27 lần số trẻ nữ (22 trẻ, chiếm $44,00 \%$ ), số trẻ 3-5 tuổi (30 trẻ, chiếm $60,00 \%$ ) gấp 1,5 lần số trẻ 6-8 tuổi (20 trẻ,chiếm 40,00\%). Trong 136 răng có chỉ

${ }^{1}$ Trường Đại hoc Y Hà Nội

${ }^{2}$ Khoa Răng Hàm Mặt, Trường Đại học Kinh Doanh và Công Nghệ

Chịu trách nhiệm chính: Trân Thị Mỹ Hạnh

Email: tranmyhanh@hmu.edu.vn

Ngày nhận bài: 10.5.2021

Ngày phản biên khoa hoc: 28.6.2021

Ngày duyệt bài: 12.7.2021 định điều trị tuỷ buồng, vi trí sâu răng hay găp nhất ở mặt nhai phối hợp mặt bển (60 răng, chiếm 44,12\%), sau đó là măt bên (46 răng, chiếm $33,82 \%$ ), ít găp nhất là mặt nhai (30 răng, chiếm 22,06\%); loại kích thước lỗ sâu hay gặp nhất là trung bình (60 răng, chiếm 44\%); ác chân răng hàm sữa ở giai đoạn I và II. Kết luận: Nghiên cứu cho thấy trong 50 bệnh nhân trẻ em được khám và điều trị tuỷ buống, số trẻ nam nhiều hơn nữ, số trẻ 3-5 tuổi hay gặp hơn trẻ 6-8 tuổi. Các răng hàm sữa có chỉ định điều trị tuỷ buồng thường có lỗ sâu ở vị trí mặt bên phối hợp mặt nhai và kích thước trung bình; chân răng ở giai đoạn I hoặc II.

Tư khóa: Điều trị tuỷ buồng, răng hàm sữa, sâu răng.

\section{SUMMARY}

\section{THE CLINIAL AND RADIOGRAPHIC SYMPTOMS OF PRIMARY MOLARS CHILDREN WITH INDICATION OF PULPOTOMY}

Objective: To assess the clinial and radiographic symptoms of primary molars among 3-8 year-old children with indication of pulpotomy. Materials and Methods: A cross-sectional study among 136 primary molars with indication of pulpotomy of 50 children age group from 3-8 years old, who are taken to School of Odonto-Stomatology, $\mathrm{Ha}$ Noi Medical University in 2019-2021 for dental examination and treatment, 
were selected. The primary teeth meeting the selective criteria were described the clinical symptoms (including: type of tooth, site and size of cavity, feature of the cavity's base), radiographic symptoms (period of physical root resorption), and general information (age and gender). Results: Among 50 pulpotomy-treated patients, the number of male children patients were higher 1,27 times than those of famale children patients, the number of 3-5-year-old patients were higher 1,5 times than those of 6-8-yearold patients. Among 136 pulpotomy-treated teeth, the most popular site of caries was on the combination of the occlusal and proximal surface; the proximal surface was lower and the occlusal one was lowest. The moderate-sized cavity was the most popular. All roots of elective teeth were at the first and second stage. Conclusion: The study showed that among 50 pulpotomy-treated patients, the number of male patients was higher than those of female, the number of 3-5-year-old patients was higher than of of 6-8-year-old patients. Among primary molars with pulpotomy-treated indication, the "proximal - occlusal" caries with moderate size were the most popular. All roots of elective teeth were at the first and second stage.

Keywords: Pulpotomy, primary molar, dental caries.

\section{I. ĐĂT VẤN ĐỀ}

Sâu răng là bênh lý răng miêng hay găp nhất ở trẻ em, trở thành vấn đề sức khoẻ cộng đồng phổ biến trên thế giới. Sâu răng được cho là bệnh nhiễm khuẩn có thể dự phòng và hồi phục ở giai đoạn đầu, nhưng nếu không được điều trị kịp thời và phù hợp, có thể ảnh hưởng tới tình trạng tuỷ răng. Những hậu quả của sâu răng sữa như: đau răng, mất sớm răng sữa, ảnh hưởng tới chu vi cung răng, giảm chức năng ăn nhau, ảnh hưởng tới thẩm mỹ, rối loân phát âm, gây ra những hậu quả ở răng vĩnh viễn và mô nha chu, nhiễm trùng, ảnh hưởng đến sự tăng trưởng và phát triển chung toàn cơ thể, mất đi sự tự tin và tốn kém chi phí cho điều trị [1],[2]. Điều tuỷ buồng là phương pháp điều trị lấy đi phần tuỷ buồng viêm nhiểm, giữ lại phần tuỷ chân lành mạnh[2]. Một trong những điểm mấu chốt quyết định tới thành công trong điều trị tuỷ buồng là việc chẩn đoán sớm, kịp thời và chính xác; dựa trển: tiền sử đau, triệu chứng cơ năng, triệu chứng thực thể và các dấu hiệu trên phim Xquang. Vì vậy, chúng tôi tiến hành nghiên cứu trên với mục đích mồ tả các đặc điểm lâm sàng và X-quang của các răng hàm sữa ở trẻ 3-8 tuổi có chỉ định điều trị tuỷ buồng.

\section{II. ĐỐI TƯợNG VÀ PHƯƠNG PHÁP NGHIÊN CỨU 1. Đối tượng nghiên cứu: \\ Tiêu chuẩn lựa chọn}

- Lố sâu răng kích thước lớn hoặc khoảng cách từ đáy lỗ sâu tới trần buồng tuỷ $<1,5 \mathrm{~mm}$ trên X-quang.

- Mô tuỷ chân còn lại chảy máu đỏ tươi. Sau khi đặt miếng bông ẩm vê nhỏ ép nhẹ lên phần tuỷ chân còn lại, có sự cầm máu hoàn toàn.

- Trẻ và gia đình hoặc người bảo hộ của trẻ đồng ý tham gia nghiên cứu.

\section{Tiêu chuẩn loai trừ}

- Đang mắc các bệnh lý toàn thân chưa được điều trị ổn định hoặc việc điều trị tuý buồng có nguy cơ làm nặng thêm các bệnh lý toàn thân, như: bệnh lý tim mạch, bệnh lý liên quan tới rối loạn quá trình đông cầm máu...

- Có các triệu chứng của viêm tuỷ không hồi phục hoặc thoái hoá mô tuỷ, như: đau tự nhiên, đau hoặc nhạy cảm khi gõ, răng lung lay bất thường, sưng nề, lỗ rò, sẹo rò...

- Có các dấu hiệu bất thường trên X-quang, như: nội tiêu, ngoại tiêu, thấu quang quanh cuống, giãn rộng dầy chằng quanh răng, calci hoá tuỷ...

- Trẻ và gia đình không thể tái khám theo đúng lịch hẹn sau 1 tuần; 1,3,6 tháng.

\section{Phương pháp nghiên cứu:}

2.1. Thiết kế nghiên cứu: Nghiên cứu mô tả cắt ngang.

2.2. Cỡ mẫu nghiên cứu: Nghiên cứu được tiến hành trên 136 răng hàm sữa ở 50 bệnh nhẩn trẻ em đạt các tiêu chuẩn lựa chọn như trên.

\subsection{Công cụ và quy trình thu thập số liệu:}

\subsubsection{Quy trinh thu thâp số liệu}

Quy trình thu thập số liệu được thực hiện theo các bước sau:

- Nhận được sự thông qua đề cương nghiên cứu và sự đồng ý của Hội đồng đạo đức nghiên cứu.

- Trao đổi, giải thích và nhận được sự đồng ý tham gia nghiên cứu của trẻ và gia đình.

- Khám bệnh, chẩn đoán và lập kế hoạch điều trị. Lựa chọn các bệnh nhân theo tiêu chuẩn lựa chọn. Ghi chép các thông tin chung, triệu chứng lâm sàng và cận lâm sàng trước điêu trị vào bệnh án.

\subsubsection{Công cụ và dụng cụ thu thập số liệu}

- Bệnh án ghi chép các thông tin cá nhân chung và các thông tin đặc thù cho nghiên cứu: răng tổn thương, vị trí và kích thước lồ sâu, giai đoạn tiêu chân răng.

- Phân loại vị trí và kích thước lỗ sâu theo phân loại Site and Size

Bảng 1. Phân loại lỗ sâu răng theo Site and Size [3]

\begin{tabular}{|c|c|c|}
\hline \multirow{2}{*}{$\begin{array}{c}\text { Site (Vị } \\
\text { trí) }\end{array}$} & 2 & Hố rãnh mặt nhai răng phía sau \\
\cline { 2 - 3 } & 3 & $1 / 3$ thân răng bên phía cố răng \\
\cline { 2 - 3 }
\end{tabular}




\begin{tabular}{|c|c|c|}
\hline & & $\begin{array}{c}\text { hoặc phân chân răng bị lộ do } \\
\text { tụt lợi }\end{array}$ \\
\hline \multirow{4}{*}{$\begin{array}{l}\text { Size } \\
\text { (Kích } \\
\text { thước) }\end{array}$} & Nhỏ & $\begin{array}{l}\text { Chưa hình thành lỗ sâu, có thể } \\
\text { chỉ cần điêu trị tái khoáng hoá }\end{array}$ \\
\hline & $\begin{array}{l}\text { Trung } \\
\text { bình }\end{array}$ & $\begin{array}{l}\text { Tổn thương sâu lớp ngà. Cấu } \\
\text { trúc răng còn lại đủ khoẻ để } \\
\text { nâng đỡ và lưu giữ miểng } \\
\text { trám phục hồi thân răng }\end{array}$ \\
\hline & Lớn & $\begin{array}{l}\text { Xoang sâu kích thước lớn, mở } \\
\text { rộng tới múi răng hoắc phần rìa } \\
\text { cắn. Tố chức mô răng còn laai } \\
\text { yếu, có thể bị gãy vỡ dưới lực } \\
\text { ăn nhai. Phương pháp phục hồi } \\
\text { thân răng đòi hỏi phải nâng đỗ } \\
\text { và bảo vệ cấu trúc mô răng } \\
\text { lành mạnh còn lại }\end{array}$ \\
\hline & $\begin{array}{l}\text { Rất } \\
\text { lớn }\end{array}$ & $\begin{array}{c}\text { Xoang sâu rất lớn, mất một } \\
\text { phân thân răng }\end{array}$ \\
\hline
\end{tabular}

-Ghế máy và dụng cụ khám cơ bản (gương, gắp, thám trâm), nạo ngà, bông.

-Áo Blouse, mũ, găng tay, khẩu trang y tế.

-Giây, bút.

3. Xử lý và phân tích số liệu. Các số liệu được nhập, xử lý và phân tích theo phần mềm thổng kề SPSS 16.0. Sử dụng thuật toán Chi square và so sánh các trung bình.

\section{KẾT QUẢ NGHIÊN CỨU}

1. Đặc điểm chung của nhóm bệnh nhân

3.1.1. Đặc điểm về giới tính

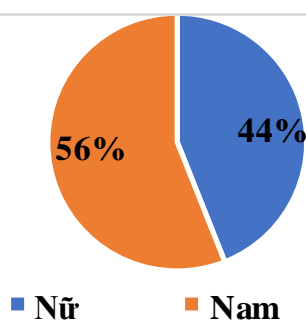

Biều đồ 1. Đặc điểm về giới tinh của nhóm bệnh nhân
Nhận xét: Trong 50 bệnh nhân trẻ em được khám và điều trị tuỷ buồng, số trẻ nam chiếm $56 \%$ cao gấp 1,27 lần số trẻ nữ. Sự khác biệt không có ý nghĩa thống kê ( $p=0,549>0,05)$.

3.1.2. Đặc điểm về tuổi

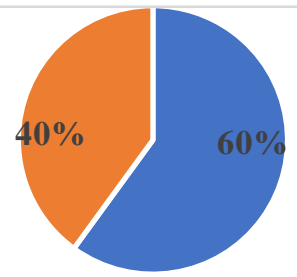

- 3-5 tuổi " 6-8 tuổi

Biều đồ 2. Đặc điểm về tuổi của nhóm bẹnh nhân

Nhận xét: Trong 50 bệnh nhân trẻ em được khám và điêu trị tuỷ buồng, $60 \%$ gặp ở trẻ 3-5 tuổi gấp 1,5 lần số trẻ 6-8 tuổi. Sư khác biêt không có ý nghĩa thống kê $(p=0,317>0,05)$.

2. Đặc điểm lâm sàng của đối tượng nghiên cứu

2.1. Đặc điểm về loại răng tổn thương Bảng 1. Đặc điểm về loại răng tổn thương

\begin{tabular}{|c|c|c|c|}
\hline Vị trí & $\begin{array}{c}\text { Răng hàm sữa } \\
\text { thứ nhất } \\
\text { n (\%) }\end{array}$ & $\begin{array}{c}\text { Răng hàm } \\
\text { sữa thứ hai } \\
\text { n (\%) }\end{array}$ & p \\
\hline \begin{tabular}{c|c|c|} 
Hàm \\
trên
\end{tabular} & $36(26,47 \%)$ & $32(23,53 \%)$ & \multirow{2}{*}{0,226} \\
\cline { 1 - 3 } $\begin{array}{c}\text { Hàm } \\
\text { dưới }\end{array}$ & $46(33,82 \%)$ & $22(16,18 \%)$ & \\
\hline
\end{tabular}

Nhận xét: Trong số 136 răng có chỉ định điều trị tuỷ buồng, loại răng hay gặp nhất là răng hàm sữa thứ nhất hàm dưới chiểm $33,82 \%$ loại răng ít gặp nhất là răng hàm sữa thứ hai hàm dưới với $16,18 \%)$. Sự khác biệt không có ý nghĩa thống kê $(p=0,226)$.

\section{2. Đặc điểm về vị trí và kích thước lỗ sâu}

Bảng 2. Tỷ lệ các vị trí sâu răng theo kích thước lỗ sâu của các răng tổn thương

\begin{tabular}{|c|c|c|c|c|c|}
\hline Tên biến & $\begin{array}{c}\text { Mặt nhai } \\
\text { n (\%) }\end{array}$ & $\begin{array}{c}\text { Mặt bên } \\
\text { n (\%) }\end{array}$ & $\begin{array}{c}\text { Phối hợp } \\
\text { n (\%) }\end{array}$ & Tổng & $\mathbf{p}$ \\
\hline Kích thước trung bình & $18(30,00 \%)$ & $40(66,67 \%)$ & $2(3,33 \%)$ & $60(100 \%)$ & \\
\hline Kích thước lớn & $10(26,32 \%)$ & $6(15,79 \%)$ & $22(57,89 \%)$ & $38(100 \%)$ & \\
\hline Kích thước rất lớn & $2(5,26 \%)$ & $0(0 \%)$ & $36(94,74 \%)$ & $38(100 \%)$ & \\
\hline Tổng & $30(22,06 \%)$ & $\begin{array}{c}46 \\
(33,82 \%)\end{array}$ & $\begin{array}{c}60 \\
(44,12 \%)\end{array}$ & $\begin{array}{c}136 \\
(100 \%)\end{array}$ & \\
\hline
\end{tabular}

Nhận xét: Trong số 136 răng có chỉ định điều trị tuỷ buồng, 44,12\% vị trí sâu răng gặp mặt nhai phối hợp mặt bên, sau đó là mặt bên, chiếm 33,82\%, ít gặp nhất là mặt nhai với 22,06\%. Loại kích thước lổ sâu hay gặp nhất là trung bình (chiếm 44\%). Sự khác biệt có ý nghĩa thống kê $(p<0,05)$.

3. Đặc điểm $X$-quang vê giai đoạn tiêu chân răng của các răng tổn thương 


\begin{tabular}{|} 
Bảng 3. Tý lệ các giai đoạn tiêu chân răng hàm sữa tổn thương theo loại răng \\
\begin{tabular}{|c|c|c|c|c|}
\hline \multirow{2}{*}{ Giai đoạn } & \multicolumn{4}{|c|}{ Loại răng tổn thương } \\
\cline { 2 - 5 } & Răng hàm sữa thứ nhất, n (\%) & Răng hàm sữa thứ hai, n (\%) \\
\cline { 2 - 5 } & Hàm trên & Hàm dưới & Hàm trên & Hàm dưới \\
\hline Giai đoạn I & $18(50 \%)$ & $30(65,22 \%)$ & $24(75 \%)$ & $16(72,73 \%)$ \\
\hline Giai đoạn II & $18(50 \%)$ & $16(34,77 \%)$ & $8(25 \%)$ & $4(27,27 \%)$ \\
\hline Tống & $36(100 \%)$ & $46(100 \%)$ & $32(100 \%)$ & $20(100 \%)$ \\
\hline
\end{tabular}
\end{tabular}

$\mathrm{p}=0,43$

Nhận xét: Trong 136 răng sữa có chỉ định lấy tuỷ buồng, tỉ lệ răng sữa ở giai đoạn I cao hơn giai đoạn Iİ, tuy nhiên sự khác biệt không có ý nghĩa thống kê $(\mathrm{p}>0,05)$.

\section{BÀN LUÂN}

1. Đặc điểm chung của nhóm bệnh nhân

1.1. Đặc điểm về giới tính. Đặc điểm về giới tính của nhóm bệnh nhân trẻ em tham gia nghiên cứu được thể hiện qua biểu đồ 3.1. Trong 50 trẻ tham gia nghiên cứu, số trẻ nam (28 trẻ) chiếm $56 \%$, cao gấp 1,3 lần số trẻ nữ (22 trẻ) chiếm $44 \%$. Điều này phù hợp với tỷ lệ giới tính khi sinh ở Việt Nam trong những năm gần đây, theo báo cáo của Tổng cục Dân số Việt Nam (2019) tỷ lệ này ước tính là 114,1 bé trai/100 bé gái.

1.2. Đặc điểm về tuổi. Đặc điểm về nhóm tuổi của nhóm bệnh nhân trẻ em tham gia nghiên cứu được thể hiện qua biểu đồ 3.2. Trong 50 bệnh nhân trẻ em được khám và điều trị tuỷ buồng, số trẻ 3-5 tuổi (30 trẻ, chiếm $60 \%$ ) gấp 1,5 lần số trẻ 6-8 tuối (20 trẻ,chiếm $40 \%$ ). Trẻ 6-8 tuổi thời gian các răng hàm sữa phơi nhiễm với các căn nguyên và yếu tố thuận lợi gây sâu răng hơn ở trẻ 3-5 tuổi - là lứa tuổi trẻ mới vừa hoàn thiện số lượng răng sữa; do vậy, đôi khi các tổn thương sâu răng lớn hơn, gâyy ảnh hưởng đến tuỷ răng nhiều hơn nên thường phải chuyển sang điều trị tuỷ toàn bộ.

2. Đặc điểm lâm sàng của đối tượng nghiên cứu

2.1. Đăc điểm về loai răng tổn thương. Trong số 136 răng có chỉ định điều trị tuỷ buồng, răng hàm sữa thứ nhất hay gặp hơn răng hàm sữa thứ hai; trong đó, răng hàm sữa thứ nhất hàm dưới gặp nhiều nhất (bảng 3.1). Điều này cũng tương đồng với kết quả nghiên cứu của Agnleszka Bruzda-Zwiech và CS (2015) [4]. Sứ khác biệt này có thể giải thích do thời điểm bắt đầu mọc răng hàm sữa thứ nhất vào lúc sớm nhất (12-16 tháng tuổi) và răng hàm dưới thường mọc trước răng cùng tên hàm trên, nên có thời gian phơi nhiềm lâu hơn với các căn nguyên và các yếu tố tấn công gây sâu răng so với các răng khác.

2.2. Đặc điểm về vị trí và kích thước lỗ sâu. Đặc điểm về vị trí và kích thước lỗ sâu của các răng hàm sữa ở nhóm bệnh nhân trẻ em tham gia nghiên cứu được thể hiện qua bảng 3.2 cho thấy: vị trí lỗ sâu hay gặp nhất ở mặt nhai phối hợp mặt bên $(60 \%)$, sau đó là mặt bển và ít gặp nhất ở mặt nhai. Điều này có thể giải thích bởi đặc điểm giải phẫu của răng hàm sữa: mặt bên tiếp xúc dang diện. lớp men và ngà răng mỏng; vì vậy tổn thương sâu răng xuất phát từ mặt bên sẽ tiến triển tới tuỷ răng nhanh hơn tổn thương sâu răng mặt nhai.

Trong 138 răng có chỉ định điều trị tuỷ buồng, loại kích thước lỗ sâu hay gặp nhất là trung bình $(60 \%)$. Điều này hoàn toàn phù hợp với nguyên tắc điều trị tổn thương sâu răng ở răng sữa. Với tổn thương sâu răng sớm (Chưa hình thành lỗ sâu) được điều trị bảo tồn bằng phương pháp tái khoáng hoá; những răng tổn thương sâu răng kích thước trung bình nhưng lớp ngà lành mạnh còn lại cách trần buồng tuỷ < $1,5 \mathrm{~mm}$ có chỉ định lấy tuỷ buồng dự phòng. Bên canhh đó, ở răng hàm sữa, cấu trúc men - ngà rằng mòng, ống ngà rộng; do đó với tổn thương sâu răng lớn sẽ tiến triển rất nhanh vào tuỷ gây viêm tuỷ không hồi phục hoặc tuỷ hoại tử có hoặc không biến chứng nha chu, khi đó có chỉ định điều trị tuỷ toàn bộ.

3. Đặc điểm $X$-quang về giai đoạn tiêu chân răng của các răng tổn thương. Kết quả bảng 3.3 cho thấy hầu hết các răng sữa có chỉ định điều trị tuỷ ở giai đoạn I, còn lại ở giai đoạn 2. Kết quả này hoàn toàn phù hợp với đă̆c điểm tiêu chân răng sữa sinh lý [5]. Thời điểm mọc các răng hàm sữa thứ nhất từ 12-16 tháng tuổi, răng hàm sữa thứ hai từ 24-36 tháng tuổi. Vì vậy, khi đánh giá ở lứa tuổi 3-8 tuổi, với các răng hàm sữa có viêm tuỷ buồng và tuỷ chân lành mạnh; các răng hàm sữa thứ nhất và thứ hai có thể ở giai đoạn I hoặc II.

\section{KẾT LUÂ̂N}

Nghiên cứu cho thấy trong 50 bệnh nhân trẻ em được khám và điều trị tuỷ buồng, số trẻ nam nhiêu hơn nữ, số trẻ 3-5 tuổi hay gặp hơn trẻ 68 tuổi. Các răng hàm sữa có chỉ định điều trị tuỷ 
buồng thường có lỗ sâu ở vị trí mặt bên phối hợp mặt nhai, kích thước lỗ sâu trung bình; chẩn răng ở giai đoạn I hoặc II.

\section{TÀI LIÊU THAM KHẢO}

1. Seale N.S. và Coll J.A. (2010). Vital pulp therapy for the primary dentition. Gent Dent. 58(3), $194-202$.

2. Tickotsky N., Petel R., Araki R. và CS. (2017). Caries Progression Rate In Primary Teeth: A Retrospective Study. J Clin Pediatr Dent, 41(5), 358-361.
3. Douglas A.Young và CS (2015). The American Dental Association Caries Classification System for Clinical Practice: A report of the American Dental Association Council on Scientific Affairs. The Journal of the American Dental Association. $146(2) ; 79-86$.

4. Agnleszka Bruzda-Zwiech và CS (2015) Caries Experience and Distribution by Tooth Surfaces in Primary Molars in the Pre-school Child Population of Lodz, Poland. al Health Prev DenT. $13(6) ; 557-566$.

5. Võ Trương Như Ngoc (2013). Răng trẻ em (dành cho đối tượng đại học). Nhà xuất bản Giáo dục.

\section{KẾT QUẢ PHẪU THUÂT NộI SOI ĐIỀU TRI VIÊM KHỚP GỐI NHIỄM KHUẨN TẠI BỆNH VIỆN BẠCH MAI}

\section{TÓM TẮT}

Mục tiêu: Đánh giá kết quả phẫu thuật nội soi điều trị viêm khớp gối nhiễm khuẩn tại Bệnh Viện Bach Mai. Đối tượng và phương pháp nghiển cứu: Nghiên cứu mô tả 57 bệnh nhân (BN) với 57 khớp gối được chẩn đoán viêm khớp gối nhiễm khuẩn, được phẫu thuật nội soi trong thời gian từ tháng 9/2018 đến hết tháng 9/2020 tai khoa Chấn thương chỉnh hình và cột sống, Bệnh viện Bạch Mai.Đánh giá kết quả sau mổ bằng thang điểm KOOS. Kết quả: Nghiên cứu có24 BN nữ (chiếm 42,1\%) và33 BN nam

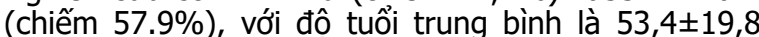
tuổi.Đánh giá kết quả sau mổ bằng thang điểm KOSS ở thời điểm sau mổ 2 tháng so với trước mổ ghi nhận: điểm KOOS triệu chứng trung bình tăng từ $42 \pm 2,87$ lên $80 \pm 2,56$, điểm KOOS đau trung bình tăng từ $42 \pm 2,87$ lên $83 \pm 2,14$, điểm KOOS chức năng, cuộc sống hàng ngày tăng từ $40 \pm 3,06$ tới $82 \pm 2,74$, điểm KOOS chức năng, hoạt động thể thao và giải trí tăng từ $24 \pm 5,56$ tới $56 \pm 5,12$ và điểm KOOS chất lượng cuộc sống tăng từ $32 \pm 3,77$ tới $79 \pm 4,01$ và điểm KOOS trung bình tăng từ $36 \pm 3,47$ tới $76 \pm 3,88$. Cải thiên điểm KOOS sau mổ 2 tháng so với trước mổ ở tất cả các phương diện có ý nghĩa thống kê với $\mathrm{p}<0,05$. Kết luận: Phẫu thuât nội soi điều tri viêm khớp gối nhiếm đem lại kết quả giảm đau tốt, cải thiên được chức năng của khớp gối và chất lượng cuộc sống cho người bênh

Tư khóa: Viêm khớp gối nhiễm khuẩn, nội soi khớp gối, Bệnh Viện Bạch Mai.

\footnotetext{
${ }^{1}$ Trường Đại học Y Hà nội

${ }^{2}$ Bênh viện Bạch Mai

Chịu trách nhiệm chính: Đào Xuân Thành

Email: daoxuanthanh@hmu.edu.vn

Ngày nhận bài: 12.5.2021

Ngày phản biên khoa học: 28.6.2021

Ngày duyệt bài: 2.7.2021
}

\section{Đào Xuân Thành ${ }^{1,2}$, Hoàng Gia $\mathrm{Du}^{2}$, Đặng Hoàng Giang ${ }^{1,2}$, Nguyễn Huy Phương ${ }^{1}$ SUMMARY \\ OUTCOMES OFARTHROSCOPIC TREATMENT FOR SEPTIC ARTHRITISOF THE KNEEIN BACH MAI HOSPITAL}

Objectives:To assess the outcomes of arthroscopic treatment for septic arthritis of the knee in Bach Mai Hospital. Subjects and Method: Descriptive study of 57 patients with 57 knee joints diagnosed septic arthritis who had arthroscopic surgery from September 2018 to September 2020 at the Department of Orthopedic \& Spine- Bach Mai Hospital. Postoperative outcomes were evaluated by the Knee injury and Osteoarthritis Outcome Score (KOOS). Results: The average age is 53.4 years with 24 female patients $(42.1 \%)$ and 33 male patients $(57.9 \%)$. Symptoms KOOS score increased from $42 \pm$ 2.87 before surgery to $80 \pm 2.562$-month after surgery. Pain KOOS score increased from $42 \pm 2.87$ to $83 \pm 2.14$. Function in daily living (ADL) KOOS score increased from $40 \pm 3.06$ to $82 \pm 2.74$. Function in Sport and Recreation (Sport/Rec) KOOS score increased from $24 \pm 5.56$ to $56 \pm 5.12$. Quality of Life (QoL) KOOS score increased from $32 \pm 3.77$ to $79 \pm$ 4.01. Average KOOS score increased from $36 \pm 3.47$ before surgery to $76 \pm 3.88$ 2-month after surgery. Conclusion: Arthroscopic treatment for septic arthritis of the knee is an effective method, results in improving the severity of pain, patient's knee function and quality of life.

Keywords: Septic arthritis, Bach Mai Hospital, knee arthroscopy

\section{I. ĐĂT VẤN ĐỀ}

Viêm khớp nhiễm khuẩn là bệnh viêm khớp do vi khuẩn có mặt trong khớp và trực tiếp gây bệnh. Viêm khớp gối nhiễm khuẩn là bệnh lý nhiễm khuẩn khớp thường gặp nhất và thường để lại nhiều di chứng xấu đến chức năng 